\title{
PARAMETERS CONTROLLING STRENGTH OF INDUSTRIAL WASTE-LIME AMENDED SOIL
}

\author{
Nilo Cesar Consoli ${ }^{\text {i) }}$, Amanda Dalla Rosa ${ }^{\text {ii) }}$ and Rodrigo Beck Saldanha ${ }^{\text {iii) }}$
}

\begin{abstract}
Unconfined compression tests and suction measurements were carried out in the present work on sandy specimens with distinct Class $\mathrm{F}$ fly ash amounts, lime contents, porosities and curing periods to assess key parameters controlling strength of fly ash-lime amended soil. A special effort has been allocated in order to develop a dosage methodology for fly ash-lime improved soils based in a rational criterion, as it exists in the concrete technology where the water/cement ratio plays a fundamental role in the assessment of the target strength. The results show that the unconfined compressive strength (UCS) increased linearly with the amount of lime for soil-fly ash-lime mixtures at all curing time periods studied. A power function fits better the relation UCS-porosity for soil-fly ash-lime mixtures. The bigger the amount of fly ash and the curing time, the larger the UCS for any given porosity and lime content. Finally, the porosity/volumetric lime content ratio, in which volumetric lime content is adjusted by a coefficient (in this case a unique value-0.12-was found for all soil-fly ash-lime mixtures and all curing periods studied) to end in single correlations for each curing period, show to be a good parameter in the evaluation of the unconfined compressive strength of the soil studied (UCS varies non-linearly with the porosity/volumetric lime content ratio in the case of fly ash-lime addition).
\end{abstract}

Key words: compaction, compressive strength, lime, soil stabilization, unconfined compression test (IGC: D9/D10)

\section{INTRODUCTION}

Engineered fills, slope protection of earth dams and subgrades for rail tracks are some of geotechnical engineering applications in which fly ash-lime treated soils find application. The development of alternatives for reusing industrial by-products (e.g., fly ash, bottom ash) mostly brings environmental, economical and technical benefits (Consoli et al., 2007a). Materials such as Class F fly ash, by-product of coal combustion in thermal power plants, are profusely produced in southern Brazil. Such residue cannot be used alone in soil stabilization applications as it is not self-cementing. Several methodologies were established in the last years (e.g., Rogers et al., 1997) in order to determine the needed amounts of lime required for modification of soil (or soil-fly ash) characteristics and introduce adequate strength and durability to the use. Such methodologies intent to establish a threshold value, supposed to chemically satisfy the soil demand for lime, which has been often suggested as the starting content to adopt for construction expediency purposes. In spite of the numerous applications, there are no dosage methodologies for the assessment of a target soil-fly ash-lime strength, based on rational criteria as in the case of soil-cement technology, where the voids/cement ratio plays a fundamental role (Consoli et al., 2007b, 2009, 2010). The need for such dosage results from the fact that soil-fly ash-lime shows a complex behavior that is affected by many factors, for example the physical-chemical properties of the soil and the fly ash, curing time, quantity of fly ash, amount of lime and porosity of the mixtures (e.g., Mitchell, 1981; Transportation Research Board (TRB), 1987; Kamon and Nontananandh, 1991; Nontananandh and Kamon, 1996; Consoli et al., 2008).

This study therefore aims to quantify the influence of curing time, amount of lime, quantity of fly ash and porosity on the strength of a sandy soil-fly ash-lime mixtures, as well as to evaluate the use of a porosity/volumetric lime content ratio to assess its unconfined compressive strength. The focus here was on the long-term effects (28, 60 and 90 days of curing) of the lime addition on the unconfined compressive strength of the soil-fly ash mixtures. The physical-chemical mechanisms of both short and long-term reactions involved in lime stabilization of soils or soil-fly ash mixtures have been extensively described in the literature (e.g., Minnick, 1967; Ingles and Metcalf, 1972; NCHRP, 1976; TRB, 1987) and are not discussed but only referred in this paper.

\footnotetext{
Associate Professor, Department of Civil Engineering, Federal University of Rio Grande do Sul, Brazil (consoli@pq.cnpq.br).

Ph.D. Student, ditto.

ii) Research Assistant, ditto.

The manuscript for this paper was received for review on March 30, 2010; approved on December 7, 2010.

Written discussions on this paper should be submitted before November 1, 2011 to the Japanese Geotechnical Society, 4-38-2, Sengoku, Bunkyo-ku, Tokyo 112-0011, Japan. Upon request the closing date may be extended one month.
} 


\section{EXPERIMENTAL PROGRAM}

The experimental program was carried out in three parts. First, the geotechnical properties of the soil, fly ash and lime were characterized. Next, the minimum amount of lime required for full stabilization, based on the modified Initial Consumption of Lime (ICL) (Rogers et al., 1997) was established. Then a number of unconfined compression tests and measurements of matric suction were carried out as discussed below.

\section{Materials}

The soil (named Botucatu residual soil-BRS) used in the present study, derived from weathered Botucatu sandstone, was obtained from the region of Porto Alegre, in southern Brazil. The results of the soil characterization tests are shown in Table 1 and the grain size curve is shown in Fig. 1. The soil is classified as low plasticity silty sand-clayey sand (SM-SC) according to the Unified Soil Classification System. X-ray diffraction showed that the fine portion is predominantly kaolinite. The soil $\mathrm{pH}$ is 5.2.

The fly ash (FA) selected (type F according to ASTM C 618 (ASTM, 1998)) was a residue of burning coal in a thermal power station, located nearby Porto Alegre. The

Table 1. Physical properties of soil sample

\begin{tabular}{l|c|c}
\hline \multicolumn{1}{c|}{ PROPERTIES } & BRS & Fly Ash \\
\hline Liquid Limit & $25 \%$ & - \\
\hline Plastic Limit & $17 \%$ & - \\
\hline Plastic Index & $8 \%$ & Non-plastic \\
\hline Specific Gravity & 2.64 & 2.28 \\
\hline Medium Sand $(0.2 \mathrm{~mm}<$ diameter $<0.6 \mathrm{~mm})$ & $16.2 \%$ & $1.0 \%$ \\
\hline Fine Sand $(0.06 \mathrm{~mm}<$ diameter $<0.2 \mathrm{~mm})$ & $45.4 \%$ & $13.6 \%$ \\
\hline Silt $(0.002 \mathrm{~mm}<$ diameter $<0.06 \mathrm{~mm})$ & $33.4 \%$ & $84.9 \%$ \\
\hline Clay (diameter $<0.002 \mathrm{~mm})$ & $5.0 \%$ & $0.5 \%$ \\
\hline Effective Diameter $\left(D_{50}\right)$ & $0.12 \mathrm{~mm}$ & $0.018 \mathrm{~mm}$ \\
\hline Uniformity Coefficient $\left(C_{\mathrm{u}}\right)$ & 45.7 & 1.7 \\
\hline
\end{tabular}

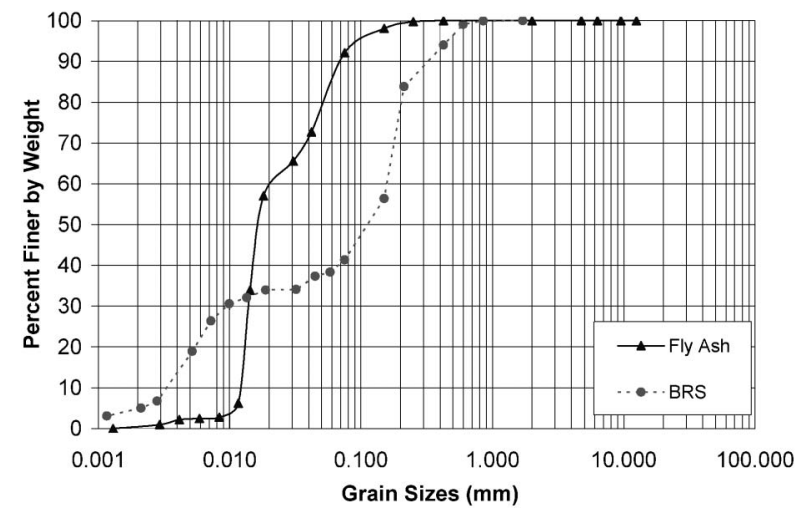

Fig. 1. Grain size distribution of BRS and fly ash main characteristic of Class F fly ash is the amount of calcium oxide $(\mathrm{CaO})$ in the ash, which is typically less than $12 \%$ (in the present case $\mathrm{CaO}$ percentage is $0.8 \%$ ). The results of the FA characterization tests are presented in Table 1 and the grain size curve is shown in Fig. 1. The material is non-plastic. The FA is classified sandy silt (ML) according to the Unified Soil Classification System. A chemical analysis has shown that the fly ash is $65.2 \%$ $\mathrm{SiO}_{2}, 23.3 \% \mathrm{Al}_{2} \mathrm{O}_{3}, 6.1 \% \mathrm{Fe}_{2} \mathrm{O}_{3}, 0.8 \% \mathrm{CaO}$ and $0.1 \%$ $\mathrm{SO}_{3}$. X-ray diffraction showed that the material is composed predominantly by amorphous minerals. The fly ash $\mathrm{pH}$ is about 8.3.

Dry hydrated lime $\left(\mathrm{Ca}(\mathrm{OH})_{2}\right)$ was used as the cementing agent. Its slow gain of strength requested the adoption of three curing time periods (28, 60 and 90 days). The specific gravity of the lime grains is 2.49 .

For the characterization tests, distilled water was used, but for molding specimens for the compression tests tap water was used.

\section{Methods}

The minimum percentage of lime (regarding dry weight of soil-fly ash) adopted in this work was established following results of Initial Consumption of Lime (ICL) method (Rogers et al., 1997). It was set up with basis on the interpretation of $\mathrm{pH}$ tests carried out on soil/fly ash with lime added-water (proportions of 1:3) mixtures. Figure 2 shows results of BRS pH variation with lime addition (ICL method), it can be observed that a minimum amount of lime of 3\% is necessary to stop $\mathrm{pH}$ variation and reach a $\mathrm{pH}$ similar to Standard solution (Standard solution is the $\mathrm{pH}$ test result carried out on lime (without soil)-water (proportions of 1:3) mixtures and establishes the maximum $\mathrm{pH}$ that could be reached due to lime insertion). Figure 2 presents also results of BRS containing $25 \%$ of Fly Ash (fly ash percentage regarding dry weight of soil)-BRS (25\% FA). It can be seen in Fig. 2 that BRS (25\% FA) mixture $\mathrm{pH}$ variation with lime addition (ICL method) results are very similar to the BRS pH tests. So, based on such results, $3 \%$ of lime is the minimum amount of lime chosen for all mixtures studied (BRS, BRS (12.5\% FA), BRS (25\% FA)), besides of 5\%, 7\% and $9 \%$ (such percentages were chosen considering international experience with soil-fly ash-lime (Mitchell, 1981;

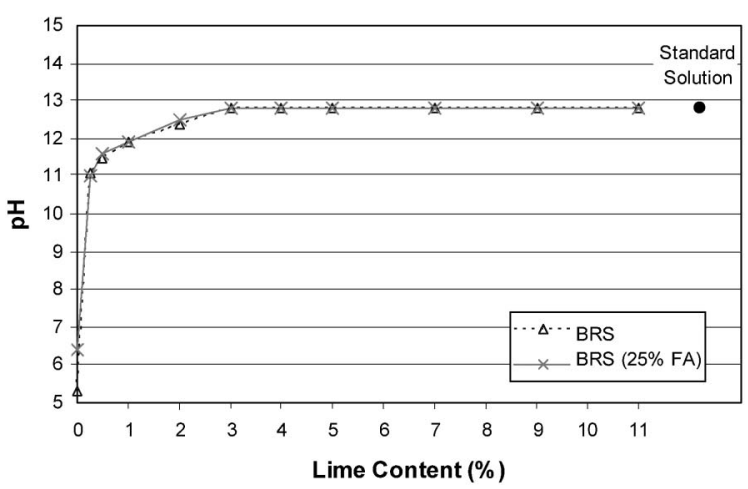

Fig. 2. Results of ICL tests for BRS and BRS (25\% FA) 
Consoli et al., 2001, 2008)).

\section{Specimens Molding and Curing}

For the unconfined compression tests cylindrical specimens, $50 \mathrm{~mm}$ in diameter and $100 \mathrm{~mm}$ high, were used. After the soil, fly ash, lime and water were weighed, the soil-fly ash (assembled in respective percentages for each specific case studied herein) and the cementitious material were mixed until the mixture acquired a uniform consistency (represented by a homogeneous appearance of the mixture and after 10 minutes of mixing). The water was then added continuing the mixture process until a homogeneous paste was created (another 5 minutes of mixing). The amount of lime for each mixture was calculated based on the mass of dry soil plus fly ash. The target moisture content for all specimens studied was $14 \%$. After mixing sufficient material for one specimen, the mixture was stored in a covered container to avoid moisture losses before subsequent compaction. The time used to prepare, mix and compact was always less than 1 hour. Two small portions of the mixture were also taken for moisture content determination. Next, following the undercompaction method proposed by Ladd (1978), each mixture was compacted in three layers into a $50 \mathrm{~mm}$ diameter cylindrical split-mould, to a target dry unit weight, moisture content and lime content (by weight of dry soil-fly ash mixtures). The top of each layer was slightly scarified. After the molding process, the specimen was immediately extracted from the split mould, and its weight, diameter, and height measured with accuracies of about $0.01 \mathrm{~g}$ and $0.1 \mathrm{~mm}$. The samples were then placed within plastic bags to avoid significant variations of moisture content. They were cured in a humid room at $23^{\circ} \mathrm{C} \pm 2{ }^{\circ} \mathrm{C}$ and relative humidity above $95 \%$ for up to 89 days. The samples were considered suitable for testing if they met the following tolerances:

- Dry unit weight within $\pm 1 \%$ of the target value;

- Moisture content within $\pm 0.5 \%$ of the target value;

- Diameter within $\pm 0.5 \mathrm{~mm}$;

- Height within $\pm 1 \mathrm{~mm}$.

It is important to point out that the dry unit weight of the specimens was calculated as the dry mass of the soil, fly ash and lime divided by the total volume of the sample. As the specific gravity of the lime is 2.49 , of the fly ash is 2.28 and of the soil is 2.64 , for the calculation of porosity, a composite specific gravity based on the soil, fly ash and lime percentages in the specimen was used.

\section{Unconfined Compression Tests}

An automatic loading machine, with maximum capacity of $50 \mathrm{kN}$ and proving rings with capacities of 10 and 50 $\mathrm{kN}$ and resolutions of 0.005 and $0.023 \mathrm{kN}$, respectively, were used for the unconfined compression tests. The displacement rate adopted was $1.14 \mathrm{~mm}$ per minute. After curing in a humid room for 27,59 or 89 days, the specimens were submerged in a water tank for $24 \mathrm{~h}$ for saturation and to minimize suction, bringing the total curing time to 28,60 or 90 days. The water temperature was controlled and maintained at $23^{\circ} \mathrm{C} \pm 2{ }^{\circ} \mathrm{C}$. Immediately be- fore the test, the specimens were taken out of the tank and dried superficially with an absorbent cloth. Then, the unconfined compression test was carried out and the maximum load reached by the specimen recorded. As acceptance criteria, it was stipulated that the individual strengths of three specimens, molded with the same characteristics, should not deviate by more than $10 \%$ from the mean strength.

\section{Matric Suction Measurement}

At their molding moisture contents all the specimens tested were in an unsaturated state and a certain level of suction may be present. The suction measurements aimed to verify its magnitude and examine if there was significant variation between specimens of different porosities and cement contents. The measured suction was the matric suction, i.e., that arising from the capillary forces inside the sample. It was measured using the filter paper technique (Marinho, 1995). The filter paper used was Whatman No. 42. Its initial moisture content, in the air dried state, is approximately $6 \%$, which allows measurements of suction from zero to $29 \mathrm{MPa}$. The calibration equations for this filter paper are those presented by Chandler et al. (1992). The matric suction measurements were performed on samples after failure in unconfined compression tests.

\section{Unconfined Compression Program of Tests}

The unconfined compression tests program was elaborated in such a way as to evaluate, separately, the influences of curing time, fly ash quantity, lime content, porosity, and voids/lime ratio on the mechanical strength of the soil-fly ash-lime mixtures. The molding points were chosen considering dry unit weights of $14 \mathrm{kN} / \mathrm{m}^{3}, 15$ $\mathrm{kN} / \mathrm{m}^{3}, 16 \mathrm{kN} / \mathrm{m}^{3}$ and $17 \mathrm{kN} / \mathrm{m}^{3}$, with the same moisture content (about $14 \%$ ). The amounts of fly ash studied in the mixtures were $0 \%, 12.5 \%$ and $25 \%$. The amounts of fly ash used in this work (up to $25 \%$ ) fall into the interval suggested by National Cooperative Highway Research Program (NCHRP) (1976) and were defined according to the regional practice, following compaction difficulties found using higher amounts of fly ash. Each point was molded with four different lime percentages: $3 \%, 5 \%$, $7 \%$ and $9 \%$. Because of the typical scatter of data for unconfined compression tests, for each point three specimens were tested. The tests were reproduced for three curing time periods: 28,60 and 90 days.

\section{RESULTS}

\section{Effect of the Fly Ash Amount, Lime Content, Porosity and Curing Time}

Tests were carried out on BRS-lime, BRS (12.5\% FA)lime and BRS (25\% FA)-lime mixtures at distinct densities, lime content and time of curing. Results of unconfined compression tests for BRS (12.5\% FA)-lime considering 28, 60 and 90 days of curing are presented in Figs. 3(a), (b) and (c), respectively. Each figure presents results considering dry densities of $14 \mathrm{kN} / \mathrm{m}^{3}, 15 \mathrm{kN} / \mathrm{m}^{3}$, 


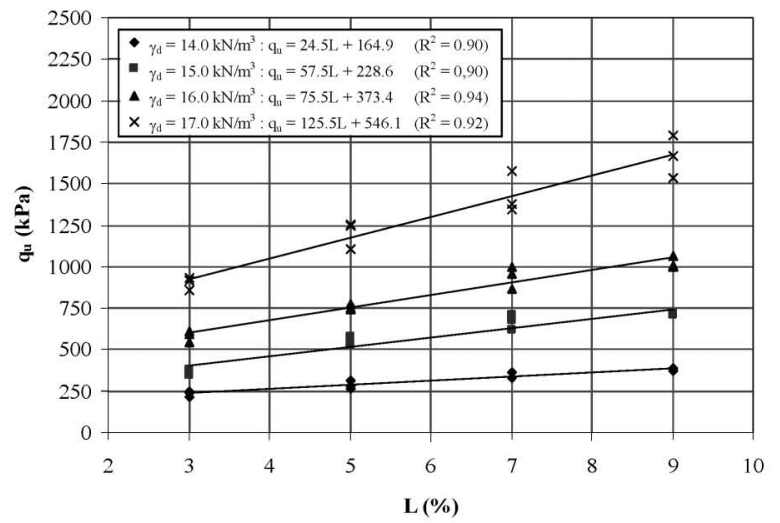

(a)

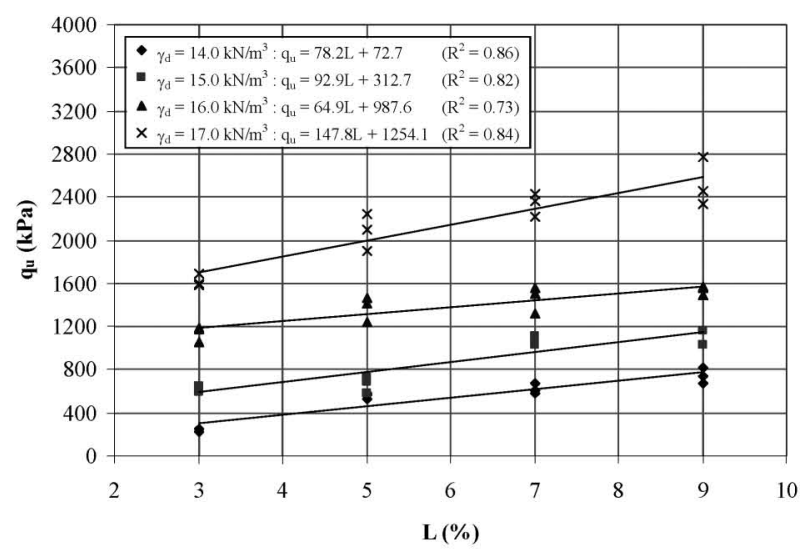

(b)

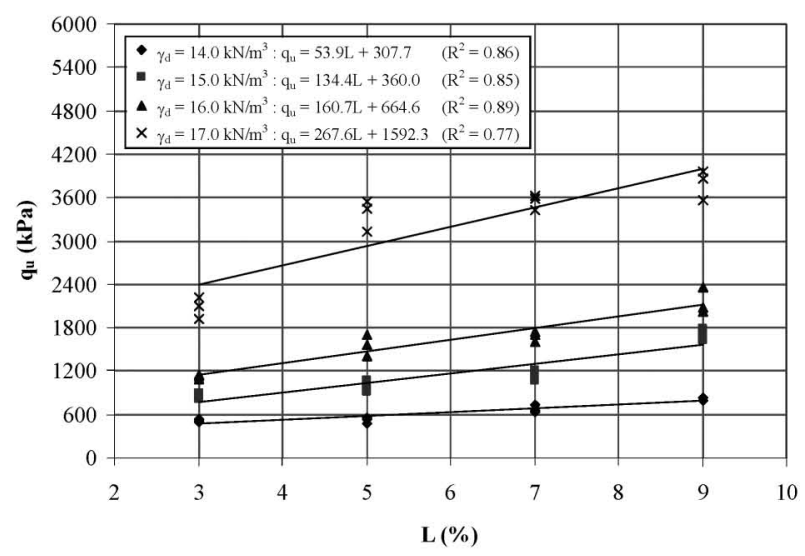

(c)

Fig. 3. Variation of unconfined compressive strength of BRS $(12.5 \%$ FA)-lime with time: (a) 28 days curing, (b) 60 days curing and (c) 90 days curing specimens

$16 \mathrm{kN} / \mathrm{m}^{3}$ and $17 \mathrm{kN} / \mathrm{m}^{3}$ and lime percentages of $3 \%$, $5 \%, 7 \%$ and $9 \%$. The larger the curing period, the bigger the unconfined compressive strength $\left(q_{\mathrm{u}}\right)$ for a given density and lime content. Linear relationships can be observed for all curing periods. In general, all studied curing periods present a slight increase in the strength gain rate with the increase of the dry unit weight.

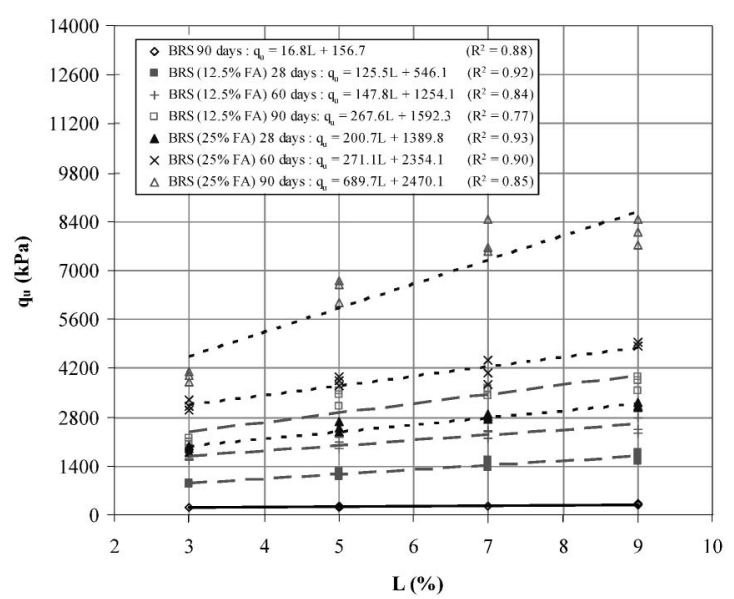

Fig. 4. Variation of unconfined compressive strength of BRS, BRS (12.5\% FA) and BRS (25\% FA) with lime content considering $\gamma_{\mathrm{d}}=$ $17 \mathrm{kN} / \mathrm{m}^{3}$ and 28,60 and 90 days curing specimens

All BRS-lime specimens for 28 and 60 days of curing disintegrate when submerged on water. Figure 4 presents results of unconfined compression tests for BRS-lime, BRS (12.5\% FA)-lime and BRS (25\% FA)-lime with lime content for $\gamma_{\mathrm{d}}=17 \mathrm{kN} / \mathrm{m}^{3}$ and 28,60 and 90 days curing specimens. The superior the amount of fly ash and curing time, the bigger the unconfined compressive strength $\left(q_{\mathrm{u}}\right)$ for a given lime content. Linear relationships can be observed for all studied soil-fly ash-lime mixtures.

Figures 5(a), (b) and (c) show how porosity affects the unconfined compressive strength of BRS (12.5\% FA)lime considering 28, 60 and 90 days of curing, respectively. The unconfined compressive strength decreases exponentially with porosity for all curing periods studied. The larger the curing period, the bigger the unconfined compressive strength $\left(q_{\mathrm{u}}\right)$ for a given lime content. The mechanism by which the reduction in porosity influences the mixtures strength is related to the existence of a larger number of contacts.

Figure 6 presents results of unconfined compression tests for BRS-lime, BRS (12.5\% FA)-lime and BRS (25\% FA)-lime with porosity for $\mathrm{L}=7 \%$ and 28,60 and 90 days curing specimens. The bigger the amount of fly ash and the curing time, the larger the unconfined compressive strength $\left(q_{\mathrm{u}}\right)$ for any given porosity. Exponential relationships can be observed for all soil-fly ash-lime mixtures at any curing time studied.

The values of suction measured were low with values ranging from about $1 \%$ up to $5 \%$ of the unconfined compressive strength. These measurements were made on the samples after failure in the unconfined compression tests and are therefore likely to overestimate the real value, because there may have been a slight drying of the sample during the few minutes from the start of the test until the measurement was made. Following small values of suction measured (when related to the respective unconfined compressive strength), such variable was not taken into account in this analysis.

To explain differences in the results when using lime on BRS, BRS (12.5\% FA) and BRS (25\% FA), it is im- 


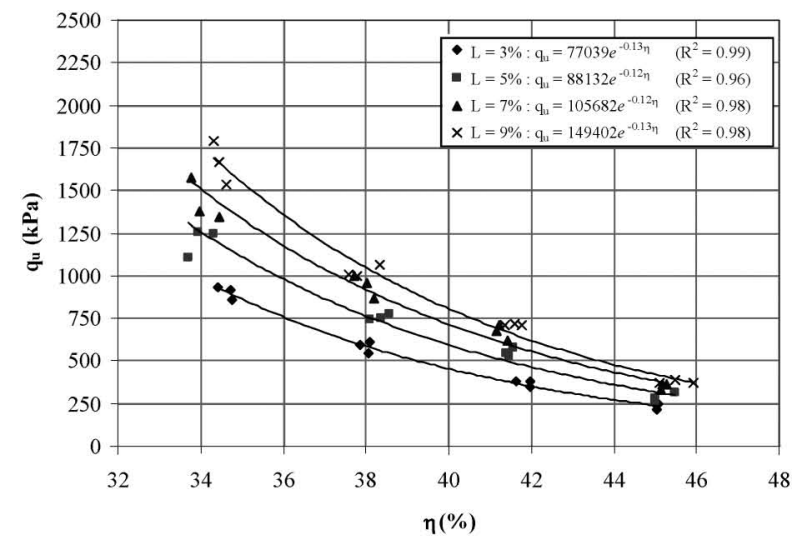

(a)

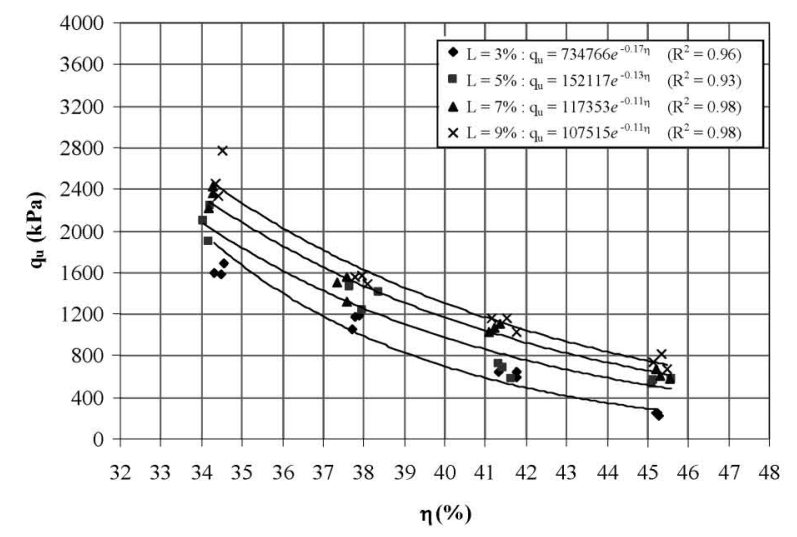

(b)

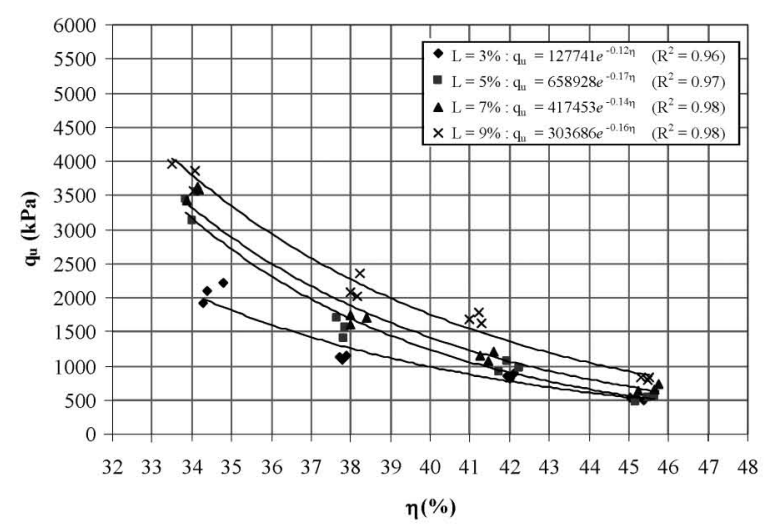

(c)

Fig. 5. Variation of unconfined compressive strength of BRS (12.5\% FA)-lime with porosity at the following curing periods: (a) 28 days, (b) 60 days and (c) 90 days specimens

portant to point out that the fine portion of BRS is formed predominantly by kaolinite minerals while FA is formed basically of amorphous minerals (without definable crystal structure). Chemically both materials are mainly formed of silica and alumina. Time-dependent chemical reactions between lime and clay/fly ash particles, namely pozzolanic reactions occur after a certain period of curing ( 90 days for BRS, and 28 days for BRS (12.5 FA) and BRS (25\% FA)). Such reactions occur be-

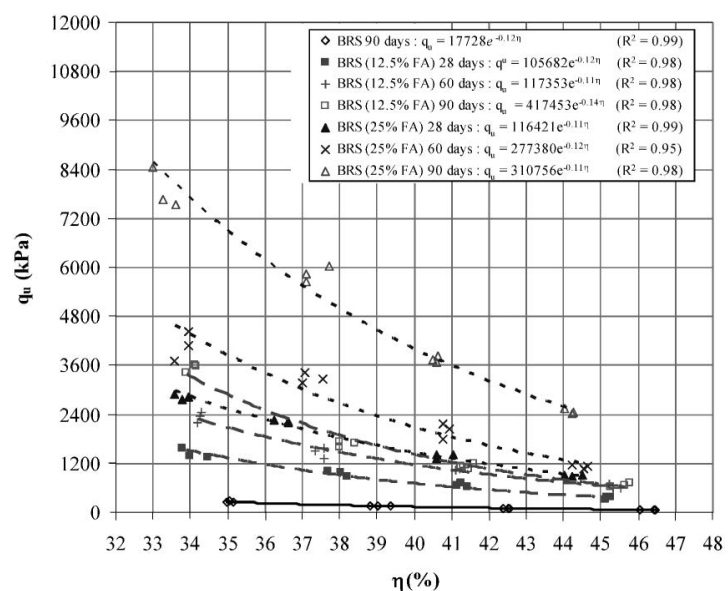

Fig. 6. Variation of unconfined compressive strength of BRS-lime, BRS (12.5\% FA)-lime and BRS (25\% FA)-lime with porosity considering $L=7 \%$ and 28,60 and 90 days curing specimens

cause silica and alumina within the clay/fly ash structure react with water and lime to form calcium silicate hydrate and calcium aluminate hydrate gels, which subsequently crystallize to bind the structure together. Insertion of fly ash in the mixture increases availability of fine amorphous minerals, enlarging the number of reactions with lime and consequently increasing strength. As shown by the results presented herein, the larger the amount of fly ash available and curing time period elapsed, the bigger the unconfined compressive strength.

\section{Effect of Porosity-Volumetric Lime Content Ratio}

As seen in the results presented above (Figs. 3 to 6), for a given curing time period and a given amount of fly ash, the unconfined compressive strength $\left(q_{\mathrm{u}}\right)$ is dependent of both the porosity and the lime content of the mixture. Rising values of porosity cause reduction of $q_{\mathrm{u}}$ while increasing values of lime content ends up in larger values of $q_{\mathrm{u}}$. It is being proposed herein the existence of an explicit relation $q_{\mathrm{u}}$ versus $\eta / L_{\mathrm{v}}$ (for each fly ash content and curing time period), being $\eta / L_{\mathrm{v}}$ defined by Eq. (1).

$$
\frac{\eta}{L_{\mathrm{v}}}=\frac{\text { Porosity }}{\text { Volumetric Lime Content }}
$$

The relation $q_{\mathrm{u}}$ versus $\eta / L_{\mathrm{v}}$ suggests that $\eta / L_{\mathrm{v}}$ joins the distinct effects of both variables $\left(\eta\right.$ and $L_{\mathrm{v}}$ ) in a unique factor controlling $q_{\mathrm{u}}$. It means that $\eta$ and $1 / L_{\mathrm{v}}$ affect separately $q_{\mathrm{u}}$ and that the effect on $q_{\mathrm{u}}$ of increasing values of porosities can be counter acted by increasing values of volumetric lime contents, ending up in $\eta / L_{\mathrm{v}}$ governing $q_{\mathrm{u}}$.

Figure 7 shows the variation between unconfined compressive strength $\left(q_{\mathrm{u}}\right)$ and the porosity/volumetric lime content $\left(\eta / L_{\mathrm{v}}\right)$ for BRS $(12.5 \%$ FA)-lime considering 28 , 60 and 90 days of curing. Reasonable correlations can be observed, in Fig. 7, between $q_{\mathrm{u}}$ and $\eta / L_{\mathrm{v}}$ for BRS $(12.5 \%$ FA)-lime considering 28 days of curing (see Eq. (2)- $\mathrm{R}^{2}=$ $0.52), 60$ days of curing (see Eq. $\left.(3)-R^{2}=0.50\right)$ and 90 days of curing (see Eq. (4) $-\mathrm{R}^{2}=0.48$ ). 


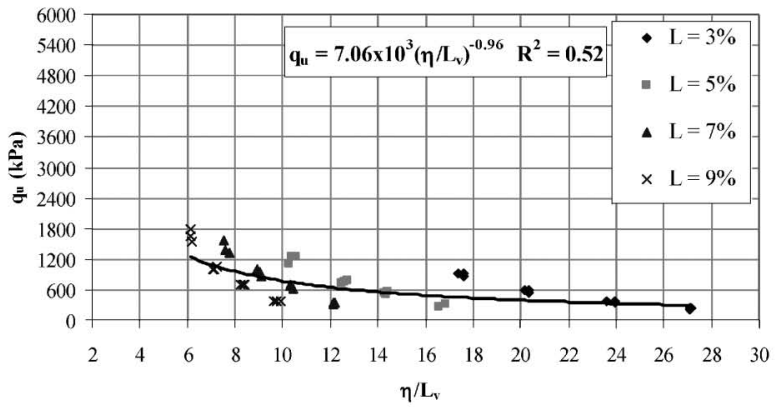

(a)

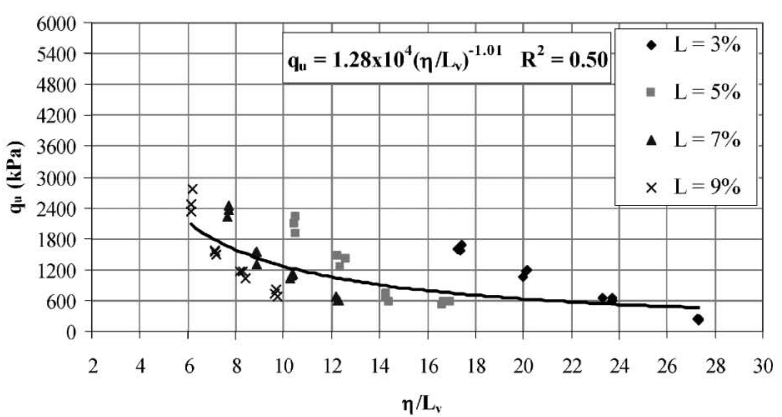

(b)

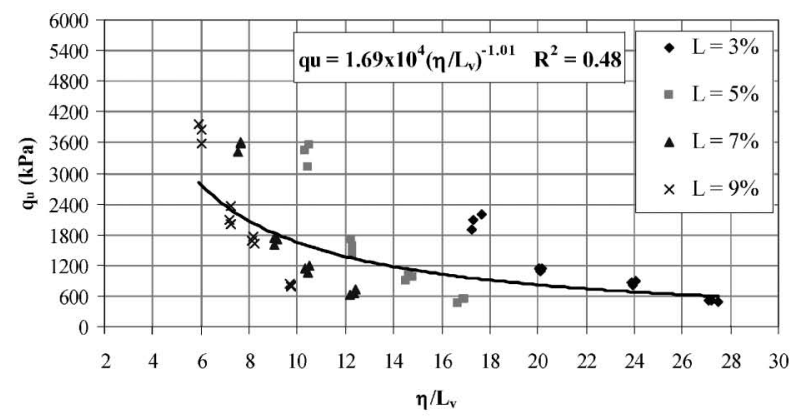

(c)

Fig. 7. Variation of unconfined compressive strength $\left(q_{\mathrm{u}}\right)$ of BRS (12.5\% FA)-lime specimens with porosity/volumetric content of lime $\left(\eta / L_{v}\right)$ at the following curing periods: (a) 28 days, (b) 60 days and (c) 90 days specimens

$$
\begin{aligned}
& q_{\mathrm{u}}(\mathrm{kPa})=7.06 \times 10^{3}\left(\frac{\eta}{L_{\mathrm{v}}}\right)^{-0.96} \\
& q_{\mathrm{u}}(\mathrm{kPa})=1.28 \times 10^{4}\left(\frac{\eta}{L_{\mathrm{v}}}\right)^{-1.01} \\
& q_{\mathrm{u}}(\mathrm{kPa})=1.69 \times 10^{4}\left(\frac{\eta}{L_{\mathrm{v}}}\right)^{-1.01}
\end{aligned}
$$

Figure 8 presents results of unconfined compression tests for BRS-lime, BRS (12.5\% FA)-lime and BRS (25\% FA)-lime with porosity for $\mathrm{L}=7 \%$ and 28,60 and 90 days curing specimens. The bigger the amount of fly ash and the curing time, the larger the unconfined compressive strength $\left(q_{\mathrm{u}}\right)$ for any given $\eta / L_{\mathrm{v}}$.

As the correlations shown in Fig. 7 for BRS (12.5\% FA)-lime were just reasonable $\left(\mathrm{R}^{2} \sim 0.50\right)$, it appeared that the rates of change of unconfined compressive strength with porosity $(\eta)$ and the inverse of the volumetric lime content $\left(1 / L_{\mathrm{v}}\right)$ were distinct. In order to make the

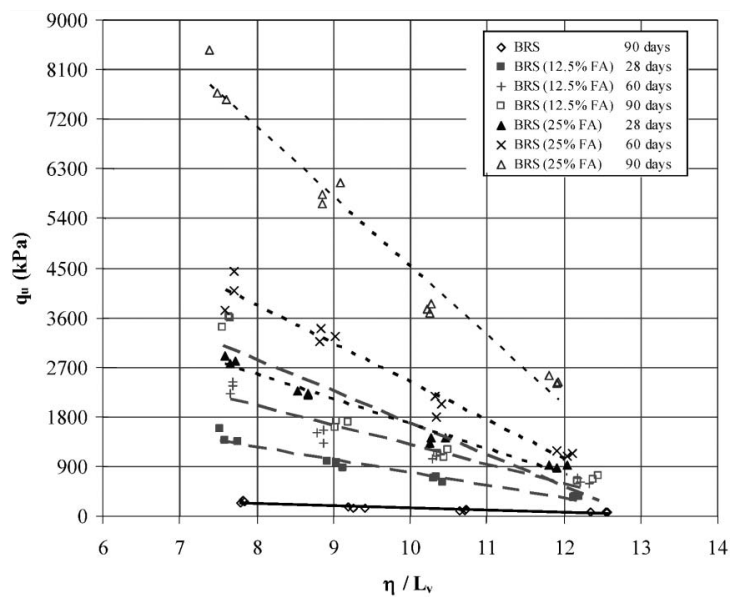

Fig. 8. Variation of unconfined compressive strength of BRS-lime, BRS (12.5\% FA)-lime and BRS ( $25 \%$ FA)-lime with porosity/volumetric content of lime considering $L=7 \%$ and 28,60 and 90 days curing specimens

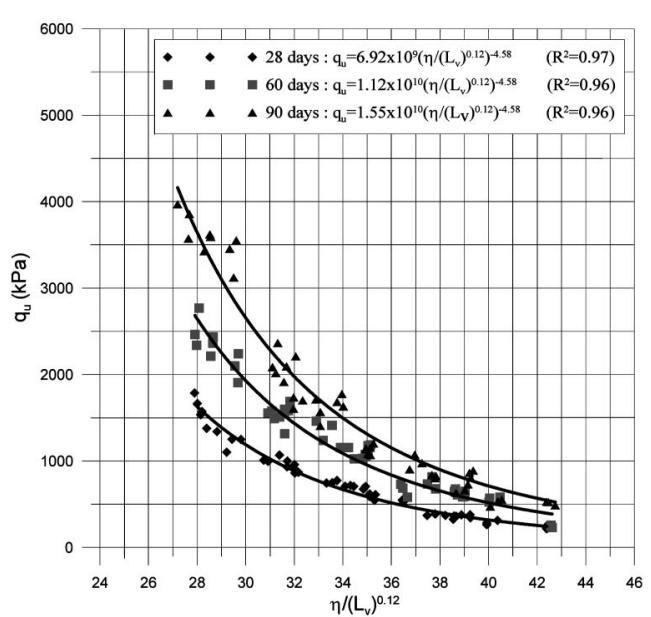

Fig. 9. Variation of unconfined compressive strength of BRS (12.5\% FA)-lime specimens with adjusted porosity/volumetric content of lime at 28 days, 60 days and 90 days curing periods

variation rates of $\eta$ and $1 / L_{\mathrm{v}}$ compatible on the effects of its variation on $q_{\mathrm{u}}$, it was found that applying a power of 0.12 on the parameter $L_{\mathrm{v}}$, for BRS (12.5\% FA)-lime at all curing periods studied, a good adjustment of the data for the unconfined compressive strength was reached as presented in Fig. 9. A good correlation between $q_{\mathrm{u}}$ and the $\eta /\left(L_{\mathrm{v}}\right)^{0.12}$ was found using a power relationship for BRS (12.5\% FA)-lime with 28 days of curing $\left(\mathrm{R}^{2}=0.97\right)$, BRS (12.5\% FA)-lime with 60 days of curing $\left(\mathrm{R}^{2}=0.96\right)$ and BRS (12.5\% FA)-lime with 90 days of curing $\left(\mathrm{R}^{2}=\right.$ 0.96) mixtures (Eqs. (5), (6) and (7), respectively). The bigger the curing time period, the larger the unconfined compressive strength $\left(q_{\mathrm{u}}\right)$ for any given $\eta /\left(L_{\mathrm{v}}^{0.12}\right)$.

$$
\begin{aligned}
& q_{\mathrm{u}}(\mathrm{kPa})=6.92 \times 10^{9}\left[\frac{\eta}{\left(L_{\mathrm{v}}\right)^{0.12}}\right]^{-4.58} \\
& q_{\mathrm{u}}(\mathrm{kPa})=1.12 \times 10^{10}\left[\frac{\eta}{\left(L_{\mathrm{v}}\right)^{0.12}}\right]^{-4.58}
\end{aligned}
$$




$$
q_{\mathrm{u}}(\mathrm{kPa})=1.55 \times 10^{10}\left[\frac{\eta}{\left(L_{\mathrm{v}}\right)^{0.12}}\right]^{-4.58}
$$

A good correlation between $q_{\mathrm{u}}$ and the $\eta /\left(L_{\mathrm{v}}\right)^{0.12}$ is also found using a power relationship for BRS (25\% FA)-lime with 28 days of curing $\left(\mathrm{R}^{2}=0.93\right)$, BRS $(25 \% \mathrm{FA})$-lime with 60 days of curing $\left(\mathrm{R}^{2}=0.88\right)$ and BRS $(25 \%$ FA)lime with 90 days of curing $\left(\mathrm{R}^{2}=0.92\right)$ mixtures (see Fig. 10 and Eqs. (8), (9) and (10), respectively). The bigger the curing time period, the larger the unconfined compressive strength $\left(q_{\mathrm{u}}\right)$ for any given $\eta /\left(L_{\mathrm{v}}^{0.12}\right)$.

$$
\begin{aligned}
& q_{\mathrm{u}}(\mathrm{kPa})=1.37 \times 10^{10}\left[\frac{\eta}{\left(L_{\mathrm{v}}\right)^{0.12}}\right]^{-4.58} \\
& q_{\mathrm{u}}(\mathrm{kPa})=2.11 \times 10^{10}\left[\frac{\eta}{\left(L_{\mathrm{v}}\right)^{0.12}}\right]^{-4.58} \\
& q_{\mathrm{u}}(\mathrm{kPa})=3.44 \times 10^{10}\left[\frac{\eta}{\left(L_{\mathrm{v}}\right)^{0.12}}\right]^{-4.58}
\end{aligned}
$$

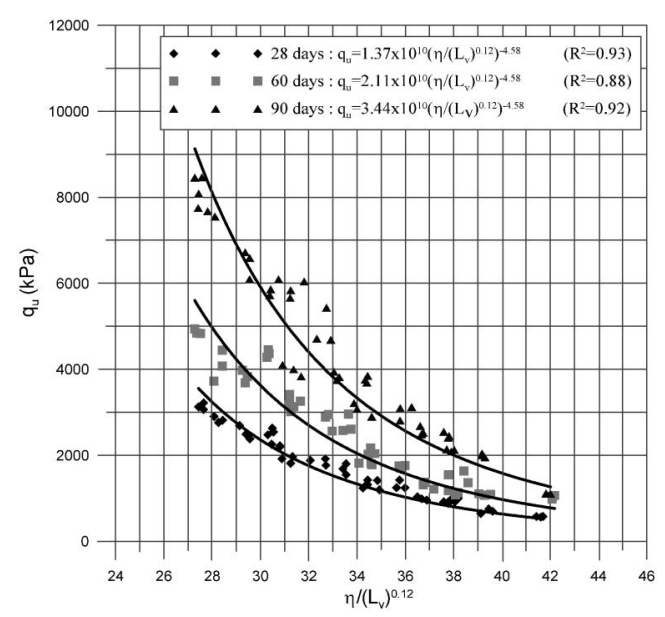

Fig. 10. Variation of unconfined compressive strength of BRS (25\% FA)-lime specimens with adjusted porosity/volumetric content of lime at 28 days, 60 days and 90 days curing periods

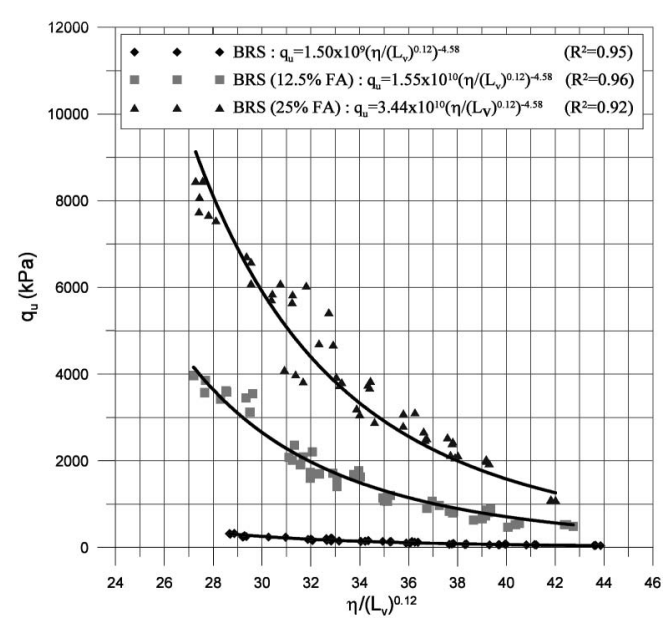

Fig. 11. Variation of unconfined compressive strength with adjusted porosity/volumetric content of lime-(curves adjusted for each one of the three $\mathrm{FA}$ content studied)
Finally, fairly good correlation between $q_{\mathrm{u}}$ and the $\eta /\left(L_{\mathrm{v}}\right)^{0.12}$ is also found using a power relationship for BRS-lime with 90 days of curing $\left(\mathrm{R}^{2}=0.95\right)$ as shown in Fig. 11 and Eq. (11). For comparison, BRS (12.5\% FA)lime with 90 days of curing and BRS (25\% FA)-lime $\left(\mathrm{R}^{2}\right.$ $=0.92$ ) with 90 days of curing mixtures are also shown in Fig. 11. It can be observed that the bigger the fly ash content, the larger the unconfined compressive strength $\left(q_{\mathrm{u}}\right)$ for any given $\eta /\left(L_{v}^{0.12}\right)$.

$$
q_{\mathrm{u}}(\mathrm{kPa})=1.50 \times 10^{9}\left[\frac{\eta}{\left(L_{\mathrm{v}}\right)^{0.12}}\right]^{-4.58}
$$

\section{DISCUSSIONS}

The results presented above indicate the existence of distinct relationships for the compacted BRS (12.5\% FA)-lime mixtures (28, 60 and 90 days of curing), for the BRS (25\% FA)-lime mixtures (28, 60 and 90 days of curing) and for the BRS-lime mixture considering 90 days of curing (all BRS-lime specimens for 28 and 60 days of curing disintegrate when submerged on water), for studied in the current research (see Figs. 9, 10 and 11). Comparing Eqs. (5), (6), (7), (8), (9), (10) and (11), it can be seen that the $q_{\mathrm{u}}$ is proportional to $\left[\eta /\left(L_{\mathrm{v}}\right)^{0.12}\right]^{-4.58}$ for the all curing time periods and the three soil-fly ash-lime mixtures and only a scalar differs regarding the effect of FA content. So, unique relationships can be achieved linking the UCS with $\eta, L_{\mathrm{v}}$ and FA content for each curing period, as presented in Fig. 12 and in Eqs. (12), (13) and (14), respectively for $28\left(\mathrm{R}^{2}=0.99\right), 60\left(\mathrm{R}^{2}=0.99\right)$ and $90\left(\mathrm{R}^{2}=\right.$ 1.0) days of curing.

$$
\begin{aligned}
& q_{\mathrm{u}}(\mathrm{kPa})=\left[1.90 \times 10^{7}+5.49 \times 10^{8}(F A)\right]\left[\frac{\eta}{\left(L_{\mathrm{v}}\right)^{0.12}}\right]^{-4.58} \\
& q_{\mathrm{u}}(\mathrm{kPa})=\left[2.30 \times 10^{8}+8.44 \times 10^{8}(F A)\right]\left[\frac{\eta}{\left(L_{\mathrm{v}}\right)^{0.12}}\right]^{-4.58} \\
& q_{\mathrm{u}}(\mathrm{kPa})=\left[6.69 \times 10^{8}+1.32 \times 10^{9}(F A)\right]\left[\frac{\eta}{\left(L_{\mathrm{v}}\right)^{0.12}}\right]^{-4.58}
\end{aligned}
$$

So, for the mixtures studied in the present research, it also can be concluded that, for each time of curing stud-

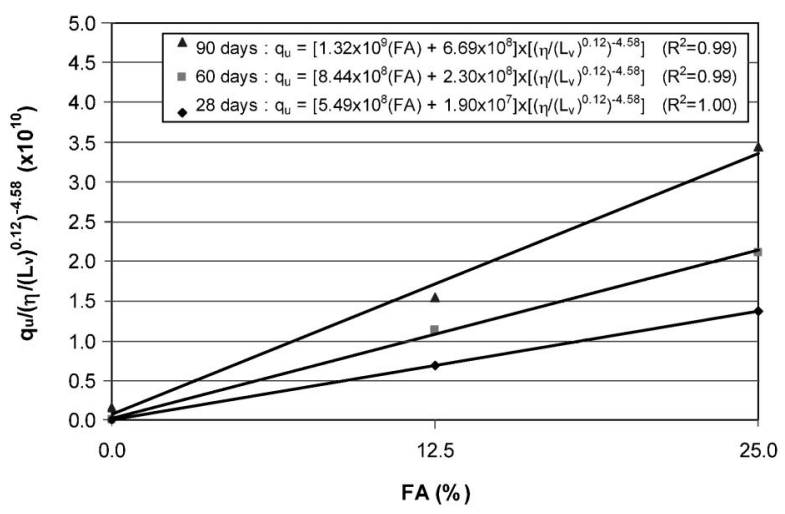

Fig. 12. Relationships for 28,60 and 90 days of curing accounting for the variation of $q_{\mathrm{u}}$ with $\eta, L_{\mathrm{v}}$ and $\mathrm{FA}$ content 
ied, the unconfined compression strength increases linearly with the increase in the fly ash content (for the FA contents studied). Equations (12) to (14) can be used as dosage relationships for the soil, fly ash and lime studied herein taking into consideration the range of curing time period from 28 to 90 days, fly ash contents ranging from zero to $25 \%$ (regarding dry weight of soil), lime contents varying from $3 \%$ to $9 \%$ (concerning dry weight of soil + fly ash) and dry unit weights ranging from $14 \mathrm{kN} / \mathrm{m}^{3}$ to 17 $\mathrm{kN} / \mathrm{m}^{3}$. Further studies are required (expanding tests to other fly ashes, limes, soils and water contents) in order to check the possibility of generalization of the present findings.

Equations (12), (13) and (14) can be used as dosage relationship. For the studied sandy soil-fly ash-lime mixtures, there are several technical ways of reaching a UCS target value for a given project: porosity reduction and/or lime content increase (always using larger amounts that the minimum requested following ICL methodology) and/or adding fly ash. The results presented in this paper therefore suggest that the engineer can choose the amount of lime, the quantity of fly ash and the compaction effort appropriate to provide a mixture that meets the strength required by the project at the optimum cost. The best option might change from situation to situation, depending of accessibility to equipment to transfer high compaction energy and availability of fly ash nearby. Finally, this methodology can also be useful in the field control of soil-fly ash-lime layers. Once a poor compaction has been recognized, it can be readily taken into account in the design, identifying through Eqs. (12) to (14) the $q_{\mathrm{u}}$ value that will be achieved, and adopting corrective measures accordingly such as the reinforcement of the treated layer or the reduction in the load transmitted.

Finally, the equations relating $q_{\mathrm{u}}$ and $\eta / L_{\mathrm{v}}$ include the effect of the water/binder ratio when the pores of the specimens were predominantly water-filled, with the amount of water reflecting the number of voids. This is similar to what happens in Portland cement concrete, where the amount of water reflects the number of voids in the mortar. In this study, the voids were only partially filled by water, and no unique relationship between the voids and the amount of water was found. Therefore, for soil-fly ash-lime in the unsaturated state, as is usual in engineering practice, the only relationship which applies to its mechanical strength, for the purposes of both analysis and control, is the one between porosity and lime volumetric content.

\section{CONCLUSIONS}

Considering the range of the variables studied (the curing time was varied from 28 to 90 days, the fly ash content was increased up to $25 \%$, the lime content was varied from 3 to $9 \%$ and the dry density was varyied from 14 to $17 \mathrm{kN} / \mathrm{m}^{3}$ ) the following conclusion can be drawn:

- The larger the fly ash content and the longer the curing period, the bigger the unconfined compressive strength $\left(q_{\mathrm{u}}\right)$ for a given density and lime content. The results of the unconfined compression tests for BRS-lime, BRS (12.5\% FA)-lime and BRS (25\% FA)-lime mixtures showed a linear relationship between these two variables.

- In all the compacted soil-fly ash-lime mixtures and all the curing periods studied, a reduction in porosity was shown to substantially increase the unconfined compressive strength. The unconfined compressive strength increased exponentially with the reduction of porosity for all the mixtures studied.

- For each curing period, an adjusted the porosity/volumetric lime content ratio (in this case adjusted to an exponent of 0.12 for each one of the three fly ash amounts and curing periods) was shown to be a good parameter in the evaluation of the unconfined compressive strength of the soil-fly ash-lime studied. A power function was quite a good fit for the relationship between the unconfined compressive strength $\left(q_{\mathrm{u}}\right)$ and adjusted porosity/volumetric content of lime [ $\eta /$ $\left.\left(L_{\mathrm{v}}\right)^{0.12}\right]$. Even when using the composition of two distinct materials (sandy soil and fly ash-BRS, BRS (12.5\% FA) and BRS (25\% FA)), the exponent 0.12 was needed for the adjustment of $q_{\mathrm{u}}-\eta / L_{\mathrm{v}}$, and this was true for all curing time periods. Such uniqueness suggests that the adjustment exponent may be a function of the lime characteristics (this was not examined in this study), but definitely is not a function of the soilfly ash matrix (at least not for the soil and fly ash used in this study) or curing time period (at least not up to 90 days of curing).

- For the soil, fly ash, lime and curing periods studied, unique relationships (Eq. (12) for 28 days of curing, Eq. (13) for 60 days of curing and Eq. (14) for 90 days of curing) were achieved linking the UCS to $\eta, L_{\mathrm{v}}$ and the FA content.

\section{ACKNOWLEDGMENTS}

The authors wish to express their gratitude to Brazilian Oil Company PETROBRAS, to the Brazilian Research Council CNPq/MCT (projects Produtividade em Pesquisa, Edital Universal, PNPD and INCT), to MEC/ CAPES and to ANEEL (project CEEE-UFRGS) for their financial support to the research group.

\section{NOTATION}

$L \quad$ lime content

$L_{\mathrm{v}} \quad$ volumetric lime content

$D_{50} \quad$ mean effective diameter

$K \quad$ constant

$q_{\mathrm{u}} \quad$ unconfined compressive strength

$\mathrm{R}^{2} \quad$ coefficient of determination

UCS unconfined compressive strength

$\Delta L_{\mathrm{v}} \quad$ variation of volumetric lime content

$\Delta \eta \quad$ variation of porosity

$\eta \quad$ porosity

$\eta / L_{\mathrm{v}}$ voids/lime ratio 


\section{REFERENCES}

1) ASTM C618 (1998): Standard Specification for Coal Fly Ash and Raw or Calcined Natural Pozzolan for Use as a Mineral Admixture in Concrete, American Society for Testing and Materials, Philadelphia.

2) Chandler, R. J., Crilly, M. S. and Montgomery-Smith, G. (1992): A low-cost method of assessing clay desiccation for low-rise buildings, Proceedings of the Institute of Civil Engineers, Civil Engineering, 92(2), 82-89.

3) Consoli, N. C., Prietto, P. D. M., Carraro, J. A. H. and Heineck K. S. (2001): Behavior of compacted soil-fly ash-carbide lime-fly ash mixtures, Journal of Geotechnical and Geoenvironmental Engineering, ASCE, 127(9), 774-782.

4) Consoli, N. C, Rotta, G. V. and Prietto, P. D. M. (2006): Yieldingcompressibility-strength relationship for an artificially cemented soil cured under stress, Géotechnique, 56(1), 69-72.

5) Consoli, N. C., Heineck, K. S., Coop, M. R., Viana da Fonseca, A. and Ferreira, C. (2007a): Coal bottom ash as a geomaterial: Influence of particle morphology on the behavior of granular materials, Soils and Foundations, JGS, 47(2), 361-373.

6) Consoli, N. C., Foppa, D., Festugato, L. and Heineck, K. S. (2007b): Key parameters for strength control of artificially cemented soils, Journal of Geotechnical and Geoenvironmental Engineering, ASCE, 133(2), 197-205.

7) Consoli, N. C., Thomé, A., Donato, M. and Graham, J. (2008): Loading tests on compacted soil-bottom ash-carbide lime layers, Proceedings of the Institute of Civil Engineers, Geotechnical Engineering, 161(1), 29-38.

8) Consoli, N. C., Viana da Fonseca, A., Cruz, R. C. and Heineck, K. S. (2009): Fundamental parameters for the stiffness and strength control of artificially cemented sand, Journal of Geotechnical and Geoenvironmental Engineering, ASCE, 135(9), 1347-1353.
9) Consoli, N. C., Cruz, R. C., Floss, M. F. and Festugato, L. (2010): Parameters controlling tensile and compressive strength of artificially cemented sand, Journal of Geotechnical and Geoenvironmental Engineering, ASCE, 136(5), 759-763.

10) Ingles, O. G. and Metcalf, J. B. (1972): Soil Stabilization-principles and Practice, Butterworths Pty. Limited, Melbourne.

11) Kamon, M. and Nontananandh, S. (1991): Combining industrial wastes with lime for soil stabilization, Journal of Geotechnical Engineering, ASCE, 117(1), 1-17.

12) Ladd, R. S. (1978): Preparing test specimens using under-compaction, Geotechnical Testing Journal, ASTM 1(1), 16-23.

13) Marinho, F. A. M. (1995): Suction measurement through filter paper technique, Proc. Unsaturated Soils Seminar, UFRGS, Porto Alegre, Brazil, 111-125 (in Portuguese).

14) Minnick, L. J. (1967): Reactions of hydrated lime with pulverized coal fly ash, Proc. Fly Ash Utilization Conference, American Public Power Association, Bureau of Mines, Pittsburgh, 287-315.

15) Mitchell, J. K. (1981): Soil improvement-State-of-the-art report, Proc. 10th Int. Conf. on Soil Mechanics and Foundation Engng, International Society of Soil Mechanics and Foundation Engineering Stockholm, 509-565.

16) National Cooperative Highway Research Program (NCHRP) (1976): Lime-fly ash stabilized bases and subbases, Synthesis of Hwy. Pract, 37, Transportation Research Board, Washington, D.C.

17) Nontananandh, S. and Kamon, M. (1996): Hydration mechanisms of fly ash stabilized by lime, Proc. 2nd Int. Conf. on Envir. Geotechnics, Balkema, Rotterdam, the Netherlands, 857-862.

18) Rogers, C. D. F., Glendinning, S. and Roff, T. E. J. (1997): Lime modification of clay soils for construction expediency, Proceedings of the Institute of Civil Engineers, Geotechnical Engineering, 125(3), 242-249.

19) Transportation Research Board (1987): Lime stabilization-reactions, properties, design, and construction, State of the art Report, 5, Transportation Research Board, Washington, D.C. 